\title{
Bilateral simultaneous percutaneous nephrolithotomy versus staged approach: a critical analysis of complications and renal function
}

\author{
(D)Fabio C. M. Torricelli \\ (iD) Regina S. Carvalho² \\ (iD) Giovanni S. Marchini' \\ (iD)Alexandre Danilovic ${ }^{1}$ \\ (iD)Fabio C. Vicentini ${ }^{1}$ \\ (iDCarlos A. Batagello \\ (iD) Miguel Srougi ${ }^{1}$ \\ William C. Nahas' \\ (iD) Eduardo Mazzucchi ${ }^{1}$
}

1. Divisão de Urologia, Departamento de Cirurgia, Faculdade Medicina da Universidade de São Paulo, São Paulo, SP, Brasil. 2. Faculdades das Américas, São Paulo, SP, Brasil.

\section{SUMMARY}

INTRODUCTION: Patients with bilateral kidney stones and burdened by large stones are challenging cases for endourologists. Simultaneous bilateral percutaneous nephrolithotomy (sbPCNL) is an option; however, it may be accompanied by important morbidity. An alternative is a staged PCNL, operating one side each time. Herein, we compare the impact of sbPCNL and staged PCNL on complication rates and renal function.

METHODS: Patients who underwent sbPCNL or staged bilateral PCNL with a frame time of 6 months were searched in our prospectively collected kidney stone database. Groups were compared for age, gender, body mass index (BMI), comorbidities (classification by the American Society of Anesthesiology - ASA), stone size, Guy's score, stone-free status, renal function, blood loss, blood transfusion rate, complication rate, and length of hospital stay.

RESULTS: Twenty-six patients and 52 kidney units were enrolled. The mean operative time was $134.7 \mathrm{~min}$. Only $11.3 \%$ of cases had complications, all of them minor (Clavien $\leq 2)$. Overall, the stone-free rate was $61.50 \%$. Comparing the groups, there was a significantly longer operative time in the sbPCNL group (172.5 vs. $126.3 \mathrm{~min} ; p=0.016)$, as well as a higher transfusion rate (12.5\% vs. 5.6\%; $p=0.036$ ). There was no statistically significant difference in creatinine levels between the groups. Regarding the stone-free rate, there was a significantly higher proportion of patients in the staged PCNL group (64.9\% vs. 43.8\%; $p=0.012$ ).

CONCLUSION: SBPCNL is a safe procedure; however, when compared to staged procedures it has a higher transfusion and lower stonefree rate.

KEYWORDS: Complications; Kidney; Lithotripsy; Urinary calculi.

DATE OF SUBMISSION: 21-Sep-2020

DATE OF ACCEPTANCE: $17-$ Oct-2020

CORRESPONDING AUTHOR: Fábio César Miranda Torricelli

Av. Vereador Jose Diniz, 3300, conj. 208, São Paulo, SP, Brasil - 04604-006

Tel: $+55115533-4900$

E-mail: fctorricelli@yahoo.com.br 


\section{INTRODUCTION}

Urolithiasis is a common disease in urological practice with a high socio-economic impact. It is estimated that approximately $10 \%$ of the worldwide population has kidney stones. In the United States, the disease affects about 1 in 11 people. ${ }^{1}$ In addition, the risk of recurrence is also high. Once diagnosed, 50\% of adult patients relapse in 5 to 10 years and $75 \%$ in 20 years. ${ }^{2}$ Recent studies have shown that the prevalence of urolithiasis has been increasing in the last decades in developed and developing countries. ${ }^{1,3}$ This trend is believed to be associated with changes in lifestyle, such as lack of physical activity, changes in eating habits, and global warming. ${ }^{4,5}$ Stones in the urinary tract can be unilateral or bilateral. The real incidence of bilateral nephrolithiasis in kidney stone formers is unknown and estimated to be from $12 \%$ to $26 \%{ }^{6}$ Thus patients with bilateral kidney stones may not be so infrequent and represent a challenge for endourologists.

Percutaneous nephrolithotomy (PCNL) replaced open renal surgery and became the treatment of choice for large $(>2.0 \mathrm{~cm})$ or complex kidney stones. ${ }^{7.8}$ As a strategy to reduce the morbidity of bilateral surgery as much as possible, traditionally, patients with large or complex bilateral kidney stones are treated in procedures performed in 2 stages, operating one side at a time. PCNL has been changed and improved, minimizing its morbidity and invasiveness, with a notable improvement in efficacy and operative time. With the implementation of new devices and technology, simultaneous bilateral PCNL (sbPCNL) has emerged as a safe and effective option. ${ }^{9}$ Recently, different authors have demonstrated favorable results with sbPCNL. ${ }^{6,10-12}$ Advantages include less sedative agents, faster return to daily activities, less need for reoperation, and shorter surgical time, decreasing the overall hospital stay and the cost of surgery. However, the lack of studies evaluating its safety compared to staged procedures makes its applicability still restricted to a few specialized centers. The concerns are increased blood loss, prolonged surgical time, and acute renal failure.

The main objective of this study is to assess renal function alteration and complication rates in patients undergoing sbPCNL in comparison to staged bilateral procedures. The secondary objective is to analyze the stone-free rate.

\section{METHODS}

Study design

After Institutional review board approval (IRB approval number 3.227.010), we searched our prospectively collected kidney stone database for patients who underwent bilateral PCNL from January 2011 through December 2018. Electronic charts were reviewed, searching for patients with bilateral stones who underwent sbPCNL or staged bilateral PCNL with a time frame of 6 months. Only patients older than 18 years were enrolled in the study. Patients with anatomical abnormalities such as pelvic kidney or ureteral duplicity were excluded, as were patients with abnormal renal function before surgery. Figure 1 shows a computed tomography scan of a patient with bilateral kidney stones eligible for bilateral PCNL.

FIGURE 1. COMPUTED TOMOGRAPHY SCAN SHOWING A LARGE BILATERAL KIDNEY STONE SUBMITTED TO BILATERAL PERCUTANEOUS NEPHROLITHOTOMY

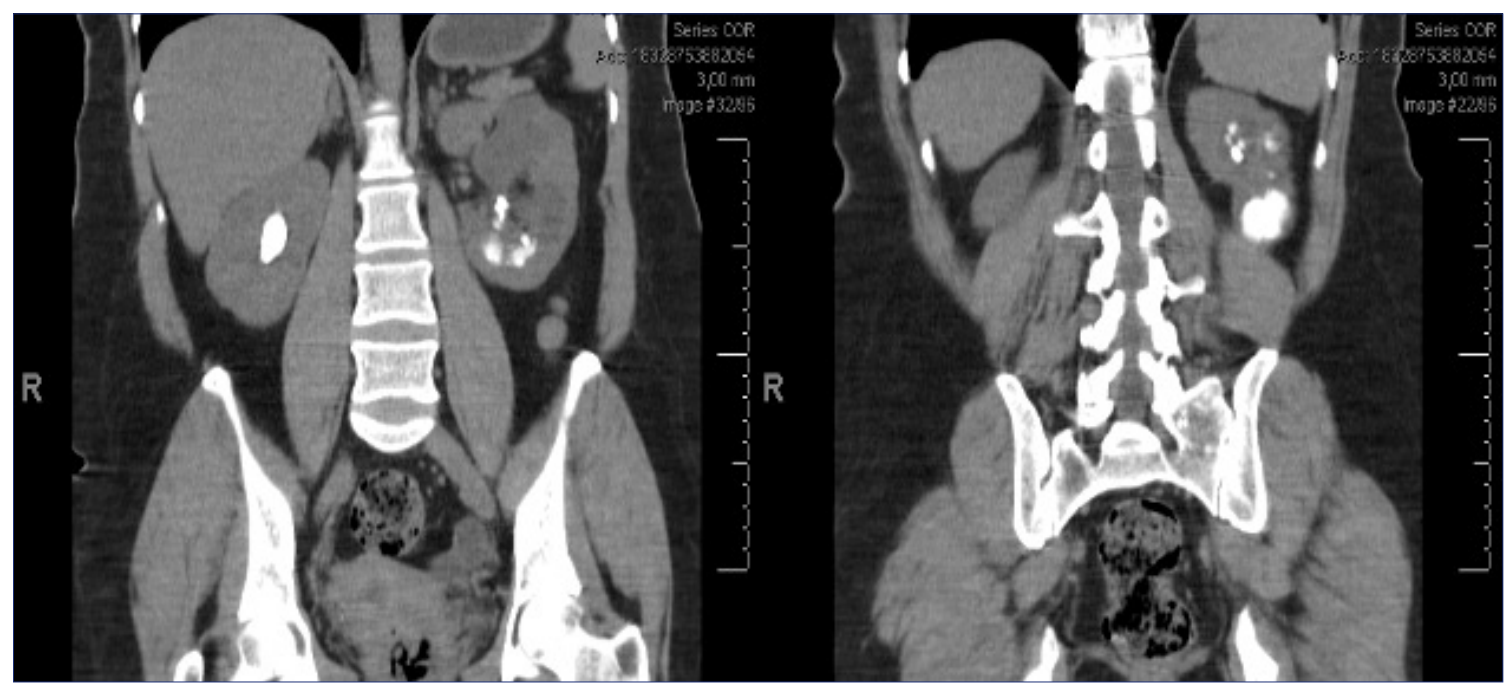


The groups were compared for age, gender, body mass index (BMI), comorbidities (classification by the American Society of Anesthesiology - ASA), stone size, Guy's stone score,$^{13}$ post-operative stone-free status, renal function, blood loss assessed by the postoperative variation of hemoglobin level, blood transfusion rate, complication rate (according to Clavien-Dindo score modified for PCNL) ${ }^{14}$ and length of hospital stay. Stone-free status was evaluated by a non-contrast computed tomography performed on the $1^{\text {st }}$ postoperative day as routinely performed in our Institution. Renal function was evaluated by the variation of creatinine level between the day before surgery, the first day after surgery, and between 30 to 60 days after the procedure.

\section{Surgical technique}

Patients with preoperative positive urine culture received appropriate antibiotic therapy for one week according to germ susceptibility, whereas patients with negative urine culture received prophylactic antibiotics (third-generation cephalosporin) starting 24 hours before surgery or at anesthesia induction.

All procedures were performed under general anesthesia. Patients were positioned in the prone or supine position based on the surgeon's preference. A 6-Fr ureteral catheter was placed through cystoscopy. After retrograde pyelography, the selected calyx was punctured under fluoroscopy guidance. A hydrophilic guidewire was inserted and passed into the ureter. If this guidewire did not reach the ureter, a PTFE guidewire was used to replace it. The tract was dilated with fascial dilators and a 30-Fr Amplatz sheath was placed. A 26-Fr rigid nephroscope was used for nephroscopy and a ultrasonic lithotripter was used for stone fragmentation and suction (Swiss LithoClast ${ }^{\circledR}$ Master, EMD, Dallas, Texas, USA). Irrigation was performed with saline solution at $25^{\circ} \mathrm{C}$ and pressure of $30-40 \mathrm{cmH}_{2} \mathrm{O}$. Flexible nephroscopy to assess residual fragments was routinely performed at the end of the procedure when conditions allowed it. An 18-Fr nephrostomy tube was placed at the end of the procedure in cases of bleeding, residual stones, renal pelvis perforation, or multiple accesses. The ureteral catheter was maintained for 12 hours in the postoperative time, or a double-J stent for one to two weeks was left in place at surgeon discretion.

Operative time was considered from the beginning of the cystoscopy for ureteral catheter placement until the end of nephrostomy tube placement. Patients with residual stones were submitted to a second look PCNL, flexible ureteroscopy, or shock wave lithotripsy based on residual stone burden and location.

\section{Statistical analysis}

Categorical data were described in frequencies, and continuous parameters were described as mean and standard deviation. Categorical variables were compared using the chi-square and Fisher exact tests, whereas continuous variables were compared using the Student t-test for independent groups. All statistical analyses were performed using SPSS version 20.0 (SPSS Inc. Chicago, IL, USA). The significance level was set at $\mathrm{p}<0.05$.

\section{RESULTS}

Twenty-six patients and 52 kidney units were enrolled in the study. The patient's mean age was 42.8 years, mean BMI was $30.1 \mathrm{Kg} / \mathrm{m}^{2}$, and $73.07 \%$ of the patients were female. Most patients were healthy - ASA 1 (53.8\%), while $46.2 \%$ had at least one comorbidity.

Overall, the mean operative time was $134.7 \mathrm{~min}$. Complications occurred in 5 cases (11.3\%; 5 of 44 surgeries), all of them minor (Clavien $\leq 2$ ). The most common complication was bleeding that required transfusion (4 cases, 7.7\%). The mean drop in hemoglobin level was $1.9 \mathrm{mg} / \mathrm{dL}$, while creatinine showed a slight increase on the $1^{\text {st }}$ postoperative day, but returned to the baseline level between the first and the second postoperative month. The transfusion rate was $7.7 \%$ and the mean hospital stay was 2.7 days. Overall, the stone-free rate was $61.50 \%$. Table 1 shows all the descriptive data.

TABLE 1. INTRA AND POSTOPERATIVE DATA.

\begin{tabular}{|c|c|}
\hline & Overall \\
\hline Operative time (min) & $134.7 \pm 49.8$ \\
\hline Complications (\%) & $11.3 \%$ \\
\hline Major Complications (Clavien $\geq 3$ ) & 0 \\
\hline Preop hemoglobin (mg/dL); mean $\pm \mathrm{SD}$ & $13.3 \pm 1.5$ \\
\hline Postop hemoglobin (mg/dL); mean \pm SD & $11.4 \pm 1.9$ \\
\hline Drop of hemoglobin (mg/dL); mean \pm SD & $1.9 \pm 1.4$ \\
\hline Blood Transfusion (\%) & $7.7 \%$ \\
\hline Length of hospital stay (days); mean \pm SD & $2.7 \pm 1.2$ \\
\hline Preop creatinine $(\mathrm{mg} / \mathrm{dL}) ;$ mean $\pm \mathrm{SD}$ & $0.9 \pm 0.3$ \\
\hline 1 POD creatinine $(\mathrm{mg} / \mathrm{dL}) ;$ mean $\pm \mathrm{SD}$ & $1.2 \pm 0.4$ \\
\hline 30-60 POD creatinine $(\mathrm{mg} / \mathrm{dL}) ;$ mean $\pm \mathrm{SD}$ & $0.9 \pm 0.3$ \\
\hline Stone-free rate $-1^{\text {st }}$ POD (\%) & $61.5 \%$ \\
\hline
\end{tabular}


Of the 26 patients, eight underwent sbPCNL and 18 underwent staged NLPC. Patients with staged NLPC were older ( 45.9 vs. 33.3 years; $p=0.028$ ); however, there were no statistically significant differences regarding gender, BMI, comorbidities (ASA score), and Guys score between the groups. Table 2 shows the demographic data of both groups. Staged PCNL was performed with a mean interval time of 34.4 days.

Comparing both groups, there was a significantly longer operative time in the sbPCNL group (172.5 vs. $126.3 \mathrm{~min} ; \mathrm{p}=0.016)$. There was a trend for more complications in the sbPCNL (25\% vs. 8.3\%; $\mathrm{p}=0.070)$; however, there was no major complication in the sbPCNL or staged PCNL groups. There was also no significant difference in the drop of hemoglobin levels (2.5 vs. 1.7 $\mathrm{mg} / \mathrm{dL} ; \mathrm{p}=0.347$ ); however, the transfusion rate was statistically significantly higher in the sbPCNL group (12.5\% vs. 5.6\%; $p=0.036)$. Regarding the length of hospital stay, there was a trend for longer hospitalization in patients with sbPCNL (3.5 vs. 2.5 days; $\mathrm{p}=0.071$ ). There was no statistically significant difference in creatinine levels between the groups. Both presented with a slight increase on the $1^{\text {st }}$ postoperative day but returned to the baseline level after one month. Regarding the stone-free rate, there was a significantly higher proportion of patients in the staged PCNL group (64.9\% vs. $43.8 \%$; $p=0.012$ ). Table 3 summarizes the comparison between the groups. Figure 2 shows the main postoperative outcomes.

\section{DISCUSSION}

According to our results, sbPCNL is a safe procedure that is not accompanied by major complications or a significant increase in the creatinine level.

\section{FIGURE 2. MAIN POSTOPERATIVE OUTCOMES OF SIMULTANEOUS AND STAGED BILATERAL PERCUTANEOUS NEPHROLITHOTOMY}

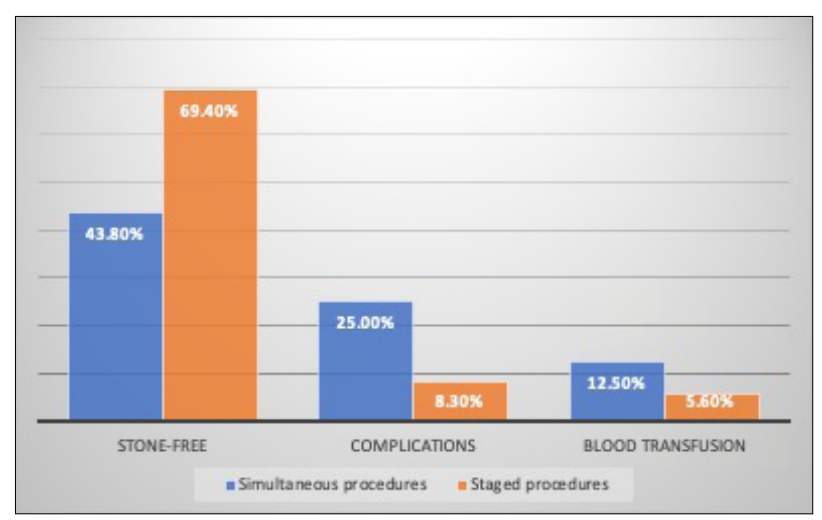

TABLE 2. DEMOGRAPHIC DATA OF SIMULTANEOUS AND STAGED-PERCUTANEOUS NEPHROLITHOTOMY.

\begin{tabular}{|c|c|c|c|}
\hline & Simultaneous procedures & Staged procedures & $\mathrm{p}$-value \\
\hline Age (years); mean \pm SD & $33.3 \pm 12.3$ & $45.9 \pm 10.6$ & 0.028 \\
\hline Gender (female) & $75.00 \%$ & $72.2 \%$ & 0.639 \\
\hline Body Mass Index (kg/m2); mean \pm SD & $31.6 \pm 5.1$ & $29.4 \pm 8.3$ & 0.424 \\
\hline ASA score & $\begin{array}{l}62.5 \% \text { ASA } 1 \\
37.5 \% \text { ASA } 2\end{array}$ & $\begin{array}{l}50 \% \text { ASA } 1 \\
50 \% \text { ASA } 2\end{array}$ & 0.437 \\
\hline Guys score (all renal units) & $\begin{array}{l}\text { Guys } 1 \\
50 \% \text { Guys } 2 \\
30 \% \text { Guys } 3 \\
20 \% \text { Guys } 4\end{array}$ & $\begin{array}{l}25 \% \text { Guys } 1 \\
25 \% \text { Guys } 2 \\
30.6 \% \text { Guys } 3 \\
19.4 \% \text { Guys } 4\end{array}$ & 0.250 \\
\hline
\end{tabular}

TABLE 3. INTRA E POSTOPERATIVE DATA OF SIMULTANEOUS AND STAGED-PERCUTANEOUS NEPHROLITHOTOMY.

\begin{tabular}{|c|c|c|c|}
\hline & Simultaneous procedures & Staged procedures & $\mathrm{p}$-value \\
\hline Operative time (min) & $172.5 \pm 59.7$ & $126.3 \pm 44.0$ & 0.016 \\
\hline Complications & $(n=2) 25.0 \%$ & $(n=3) 8.3 \%$ & 0.070 \\
\hline Major Complications (Clavien $\geq 3$ ) & $0,00 \%$ & $0,00 \%$ & 1,000 \\
\hline Preop hemoglobin (mg/dL); mean \pm SD & $13.1 \pm 1.4$ & $13.4 \pm 1.5$ & 0.663 \\
\hline Postop hemoglobin (mg/dL); mean \pm SD & $10.6 \pm 1.9$ & $11.6 \pm 1.9$ & 0.221 \\
\hline Drop of hemoglobin (mg/dL); mean \pm SD & $2.5 \pm 1.9$ & $1.7 \pm 1.2$ & 0.347 \\
\hline Blood Transfusion & $12.5 \%$ & $5.6 \%$ & 0.036 \\
\hline Length of hospital stay (days); mean \pm SD & $3.5 \pm 1.1$ & $2.5 \pm 1.2$ & 0.071 \\
\hline Preop creatinine $(\mathrm{mg} / \mathrm{dL}) ;$ mean \pm SD & $0.9 \pm 0.3$ & $0.9 \pm 0.3$ & 0.967 \\
\hline 1 POD creatinine $(\mathrm{mg} / \mathrm{dL}) ;$ mean $\pm \mathrm{SD}$ & $1.0 \pm 0.5$ & $1.2 \pm 0.4$ & 0.5 \\
\hline 30-60 POD creatinine (mg/dL); mean \pm SD & $0.8 \pm 0.2$ & $0.9 \pm 0.3$ & 0.45 \\
\hline Stone-free rate & $43.8 \%$ & $69.4 \%$ & 0.012 \\
\hline
\end{tabular}


However, when compared to staged procedures, we observed a trend for more minor complications, a higher transfusion rate and a lower stone-free rate in the sbPCNL group. To our knowledge, we present one of the few comparative studies available regarding this subject.

Other authors have already shown favorable outcomes with sbPCNL. ${ }^{9-12,15-17}$ Adhikari et al published a descriptive study with 52 patients submitted to sbPCNL and reported a success rate of $94 \%$ when considering residual fragments up to $4 \mathrm{~mm}$. In this study, almost $85 \%$ of cases were Guys 1 or 2 , which means cases of low complexity. In our study, almost $50 \%$ were complex cases, which lead us to a success rate close to $65 \%$. In accordance with our data, those authors also reported a relatively low hemoglobin drop and no significant change in serum creatinine levels. Differently of our findings, those authors had two major complications; one patient had hydrothorax that required thoracic drainage and another required surgical evacuation of clots from the bladder. ${ }^{12}$ Sofer et al, in a comparative study of bilateral versus unilateral PCNL, showed that SbPCNL is associated with a significantly increased postoperative creatinine level, a decreased postoperative hemoglobin level, a higher blood transfusion rate (9\% versus $2 \%$ ), and a longer hospital stay. ${ }^{15}$ In our study, there was no significant difference in postoperative serum creatinine between simultaneous and staged procedures; however, we also found a higher transfusion rate and a tendency for longer hospital stays in sbPCNL. Rivera et al, in another study comparing bilateral versus unilateral PCNL, reported that patients submitted to sbPCNL had longer procedures, were more likely to undergo a secondary procedure, and had a longer hospital stay. Notably, there were no differences in the number or the severity of complications between the groups. ${ }^{18}$ These findings are very similar to ours, which leads us to conclude that staged procedures have outcomes that are very close to those found in unilateral procedures.

In a systematic review of studies reporting sbPCNL outcomes, including descriptive reports, the authors found a mean initial stone-free rate of $72.6 \%$ with a mean operative time of 171.1 minutes and mean hospital stay of 3.9 days. The mean complication rate per study was $23.4 \%$ and most were Clavien grade $1 .{ }^{16}$ Once again, these findings are close to those presented in our study. However, when compared to staged procedures, we could note that transfusion rate and minor complications are higher in sbPCNL. That may be the key for an optimal outcome, recognizing when bilateral kidney stones can be treated at the same time and when procedures should be planned in two stages. This decision is not always easy and may require surgeon experience.

The literature reports one study comparing the outcomes of sbMini-PCNL versus staged bilateral MiniPCNL. ${ }^{17}$ Simultaneous procedures had a significantly shorter cumulative operative time, shorter cumulative hospital stay, and higher hemoglobin loss than staged surgeries. There were no differences between the groups for blood transfusion and complication rates. ${ }^{17}$ In our comparative study, there was a higher transfusion rate and a tendency for a higher minor complication rate in sbPCNL, this could be explained by the fact that we performed the conventional $30 \mathrm{Fr}$ approach to both kidneys and not a small tract as in Mini-PCNL.

Our study has limitations, such as its retrospective design and small sample size, which makes our comparison between the two groups limited. However, simultaneous bilateral PCNL is not a daily approach. In our Institution, we opt for simultaneous bilateral procedures in selected cases, such as those of patients with no co-morbidities and stones classified as Guys I or II bilaterally.

\section{CONCLUSION}

sbPCNL is a safe procedure; however, when compared to staged procedures it has a higher transfusion and lower stone-free rates. sbPCNL should be reserved for selected cases.

\section{Acknowledgments \\ None}

\section{Author disclosure statement}

No competing financial interests exist.

\section{Author's Contribution}

Fabio C. M. Torricelli - drafting of the manuscript and study design; Regina S. Carvalho - drafting of the manuscript; Giovanni S. Marchini, Alexandre Danilovic, Fabio C. Vicentini, Carlos A. Batagello, - data acquision; Miguel Srougi, William C. Nahas, - supervision; Eduardo Mazzucchi - critical review. 


\section{RESUMO}

INTRODUÇão: Paciente com cálculos renais bilaterais e de grande volume são casos desafiadores para os endourologistas. A nefrolitotripsia percutânea bilateral simultânea (NLPbs) é um opção, entretanto esse procedimento pode ser acompanhado de morbidade importante. Uma alternativa é a NLP estagiada, operando um lado de cada vez. Aqui, nós comparamos o impacto da NLPbs e da NLP estagiada nas taxas de complicações e função renal.

MÉTODOS: Pacientes que foram submetidos a NLPsb ou NLP stagiada com intervalo de até 6 meses foram pesquisados em nossa base de dados de cálculos renais prospectivamente coletada. Os grupos foram comparados em idade, gênero, índice de massa corpórea (IMC), comorbidades (classificação da Sociedade Americana de Anestesiologia - ASA), tamanho do cálculo, Classificação de Guys, taxa de pacientes livres de cálculos, função renal, perda sanguínea, taxa de transfusão, taxa de complicações e tempo de internação hospitalar.

RESULTADOS: Vinte e seis paciente e 52 unidades renais foram incluídas. O tempo operatório médio foi de 134,7 min. Apenas 11.3\% dos casos tiveram complicações, sendo todas menores (Clavien $\leq 2)$. No geral, a taxa de pacientes livres de cálculos foi de 61,5\%. Comparando os grupos houve um tempo operatório significativamente maior no grupo NLPbs(172,5 vs. 126,3 min; p=0,016), assim como uma maior taxa de transfusão (12,5\% vs. 5,6\%; p=0.036). Não houve diferença significante nos níveis de creatinina entre os grupos. Em relação a taxa de doentes livre de cálculos houve uma proporção significativamente maior de pacientes livres de cálculos na NLP estagiada (64,9\% vs. 43,8\%; $p=0,012)$.

CONCLUSÃO: A NLPSb é um procedimento seguro, entretando quando comparada ao procedimento estagiado apresenta uma maior taxa de transfusão e uma menor taxa de pacientes livres de cálculos.

PALAVRAS CHAVES: Complicações; Rim; Litotripsia, Cálculo urinário.

\section{REFERENCES}

1. Scales CD, Ir., Smith AC, Hanley IM, Saigal CS, Urologic Diseases in America P. Prevalence of kidney stones in the United States. Eur Urol. 2012;62(1):160-165.

2. Ferraro PM, Curhan GC, D'Addessi A, Gambaro G. Risk of recurrence of idiopathic calcium kidney stones: analysis of data from the literature. J Nephrol. 2017;30(2):227-233.

3. Marchini GS, Mello MF, Levy R, Vicentini FC, Torricelli FC, Eluf-Neto ], et al. Contemporary Trends of Inpatient Surgical Management of Stone Disease: National Analysis in an Economic Growth Scenario. J Endourol. 2015;29(8):956-962.

4. Ferraro PM, Taylor EN, Gambaro G, Curhan GC. Dietary and Lifestyle Risk Factors Associated with Incident Kidney Stones in Men and Women. J Urol. 2017;198(4):858-863.

5. Scales CD, Jr., Tasian GE, Schwaderer AL, Goldfarb DS, Star RA, Kirkali Z. Urinary Stone Disease: Advancing Knowledge, Patient Care, and Population Health. Clin J Am Soc Nephrol. 2016;11(7):1305-1312.

6. Narváez A, Torrecilla C, Colom S, Cuadrado |M, Fernández-Concha |, Riera $L$, et al. Simultaneous bilateral percutaneous nephrolithotomy: Effectiveness and safety. Actas Urol Esp. 2018;42(5):316-322.

7. Ziemba JB, Matlaga BR. Guideline of guidelines: kidney stones. BJU Int. 2015;116(2):184-189.

8. Türk C, Petřík A, Sarica K, Seitz C, Skolarikos A, Straub M, et al. EAU Guidelines on Interventional Treatment for Urolithiasis. Eur Urol. 2016;69(3):475-482.

9. Silverstein AD, Terranova SA, Auge BK, Weizer AZ, Delvecchio FC, Pietrow $P K$, et al. Bilateral renal calculi: assessment of staged $v$ synchronous percutaneous nephrolithotomy. J Endourol. 2004;18(2):145-151.

10. Shah HN, Kausik VB, Hegde SS, Shah JN, Bansal MB. Safety and efficacy of bilateral simultaneous tubeless percutaneous nephrolithotomy. Urology. 2005;66(3):500-504.
11. Darabi MR, Soltani S, Rezayat AA, Yousefi M, Kashefi M, Tavakkoli M, et al. Clinical outcomes of the simultaneous bilateral percutaneous nephrolithotomy $(\mathrm{PCNL})$ in patients with kidney stones: A prospective cohort study. Electron Physician. 2018;10(2):6377-6382.

12. Adhikari MB, Karna S, Kasaju A. Safety and Efficacy of Bilateral Simultaneous Percutaneous Nephrolithotomy. J Nepal Health Res Counc. 2019;17(1):114-118.

13. Thomas K, Smith NC, Hegarty N, Glass JM. The Guy's stone score--grading the complexity of percutaneous nephrolithotomy procedures. Urology. 2011;78(2):277-281.

14. Labate G, Modi P, Timoney A, Cormio L, Zhang X, Louie M, et al. The percutaneous nephrolithotomy global study: classification of complications. J Endourol. 2011;25(8):1275-1280.

15. Sofer M, Proietti S, Bar-Yosef Y, Dekalo S, Rosso M, Mintz I, et al. Assessment of bilateral supine and prone tubeless percutaneous nephrolithotomy. Can J Urol. 2017;24(6):9114-9120.

16. Jones P, Dhliwayo B, Rai BP, Mokete M, Amitharaj R, Aboumarzouk OM, et al. Safety, Feasibility, and Efficacy of Bilateral Synchronous Percutaneous Nephrolithotomy for Bilateral Stone Disease: Evidence from a Systematic Review. J Endourol. 2017;31(4):334-340.

17. EISheemy MS, Ghoneima W, Elmarakbi AA, AI-Kandari AM, Ibrahim $H$, Shrestha S, et al. Bilateral Single-session vs Staged Mini-percutaneous Nephrolithotomy for Renal Stones: A Comparative Study. Urology. 2018;120:62-67.

18. Rivera ME, Bhojani N, Heinsimer K, El Tayeb MM, Paonessa JE, Krambeck $A E$, et al. A Survey Regarding Preference in the Management of Bilateral Stone Disease and a Comparison of Clavien Complication Rates in Bilateral vs Unilateral Percutaneous Nephrolithotomy. Urology. 2018;111:48-53. 